\title{
Revolving images and multi-image keys open new horizons in descriptive taxonomy: ZooKeys working examples
}

\author{
Pavel Stoev', Lyubomir Penev ${ }^{2}$, Nesrine Akkari³ ${ }^{3}$ David Koon-Bong Cheung ${ }^{3}$, \\ Henrik Enghoff ${ }^{3}$, Adam Brunke ${ }^{3}$, Carina Mara de Souza ${ }^{4}$, Thomas Pape ${ }^{3}$, \\ Daniel Mietchen ${ }^{5}$, Terry Erwin ${ }^{6}$
}

\begin{abstract}
I National Museum of Natural History, Bulgarian Academy of Sciences and Pensoft Publishers, 12, Prof. Georgi Zlatarski St., 1700 Sofia, Bulgaria 2 Institute of Biodiversity and Ecosystem Research, Bulgarian Academy of Sciences and Pensoft Publishers, 12, Prof. Georgi Zlatarski St., 1700 Sofia, Bulgaria 3 Natural History Museum of Denmark (Zoological Museum), University of Copenhagen, Universitetsparken 15, Copenhagen, Denmark, 21004 Department of Animal Biology, Institute of Biology, State University of Campinas (UNICAMP), Barão Geraldo, Campinas, São Paulo, Brazil, P.O.B. 6109, 13083-970 5 Museum für Naturkunde - Leibniz-Institut für Evolutions- und Biodiversitätsforschung, Invalidenstraße 43, 10115 Berlin, Germany and Pensoft Publishers, 12, Prof. Georgi Zlatarski St., 1700 Sofia, Bulgaria 6 Department of Entomology, MRC 187, National Museum of Natural History, Smithsonian Institution, P. O. Box 37012, Washington, DC 20013-7012 USA

Corresponding author: Pavel Stoev (pavel.e.stoev@gmail.com)
\end{abstract}

Received 28 August 2013 | Accepted 30 August 2013 | Published 3 September 2013

Citation: Stoev P, Penev L, Akkari N, Cheung DK-B, Enghoff H, Brunke A, de Souza CM, Pape T, Mietchen D, Erwin T (2013) Revolving images and multi-image keys open new horizons in descriptive taxonomy: ZooKeys working examples. ZooKeys 328: 1-3. doi: 10.3897/zookeys.328.6171

Illustrations are indispensable in the recognition of species, irrespective of whether they are used for taxonomic, biological or conservational purposes. With the development of Web 2.0 and Open Access publishing, the demand for image quality and methods for visualizing taxonomic traits has significantly increased. Since its launch in 2008, ZooKeys has been supporting the development of new methods in taxonomy and advocating new tools for the visualization of taxonomic content. Publishing interactive keys as part of taxonomic revisions has become a routine practice for the journal (see e.g., Sharkey et al. 2009a,b, van Noort and Johnson 2009, Stoev et al. 2010, Cerretti et al. 2012). With the development of the journal's web platform, ZooKeys has also started to support the publication of various types of multimedia and audio records, either as supplementary materials or as files embedded in the paper itself (see e.g. Hertz et al. 2012, Faulwetter et al. 2013, Akkari et al. 2013).

Copyright Pavel Stoev et al. This is an open access article distributed under the terms of the Creative Commons Attribution License 3.0 (CC-BY), which permits unrestricted use, distribution, and reproduction in any medium, provided the original author and source are credited. 
A novel approach for the visualization of taxonomic traits exemplified by a modern revision of millipedes of the genus Ommatoiulus is published in this issue of ZooKeys (Akkari et al. 2013), along with a detailed technical description and applied workflow (Cheung et al. 2013). It presents an innovative case study aiming to overcome the challenges faced by taxonomists in describing the complex structures essential for species description and identification. The authors use multiple techniques, including an interactive key and a new rotatable scanning electron microscope (rSEM) model to meet these challenges. They present a key design which prioritizes the visual delivery of taxonomic information via interactive media, including line drawings, photographs and scanning electron micrographs of the male genitalia (gonopods). The development of rSEM is widely accessible, requiring no more than access to a scanning electron microscope and some form of software for image integration (Flash, Java Script based programs, etc.). This technique is used for the first time to enhance taxonomic descriptions and allows the structure in question to be seen from multiple angles of view.

The yet slow rate of utilization and acceleration of multimedia in taxonomic research is very likely due to the perception that sophisticated imaging requires special software, e-infrastructure, and significant funding. The method applied here proves that wrong as it enables the visualization of important taxonomic characters in great detail from various angles and can be achieved comparatively effortlessly with conventional technology and software. In addition to providing new insights on the application of SEM and bringing a touch of modernism to taxonomic studies in general, the use of detailed rotating illustrations for small and complex anatomical structures, such as millipede genitalia, revealed diagnostic characters that would have remained unnoticed with conventional methods. The use of these rSEM as a replacement for static illustrations in taxonomic revisions puts us one step closer to the development of a software capable of automatically extracting morphological character data from images of organisms and providing users with the species name (La Salle et al. 2009). Though conceived only to better visualize surface structures, the rSEM model is in a way proving that creating three-dimensional imaging libraries and virtual specimen collections is possible, with a rapid access to "cybertypes," a term recently introduced by Faulwetter et al. (2013).

\section{Acknowledgments}

Pensoft has received financial support by the ViBRANT (Virtual Biodiversity Research and Access Network for Taxonomy, www.vbrant.eu) FP7 project. 


\section{References}

Akkari N, Cheung DK-B, Enghoff H, Stoev P (2013) Revolving SEM images visualising 3D taxonomic characters: application to six species of the millipede genus Ommatoiulus Latzel, 1884, with description of seven new species and an interactive key to the Tunisian members of the genus (Diplopoda, Julida, Julidae). ZooKeys 328: 5-45. doi: 10.3897/zo okeys.328.5763

Cerretti P, Tschorsnig H-P, Lopresti M, Di Giovanni F (2012) MOSCHweb - a matrix-based interactive key to the genera of the Palaearctic Tachinidae (Insecta, Diptera). ZooKeys 205: 5-18. doi: 10.3897/zookeys.205.3409

Cheung DK-B, Brunke AJ, Akkari N, Souza CM, Pape T (2013) Rotational Scanning Electron Micrographs (rSEM): A novel and accessible tool to visualize and communicate complex morphology. ZooKeys 328: 47-57. doi: 10.3897/zookeys.328.5768

Faulwetter S, Vasileiadou A, Kouratoras M, Dailianis T, Arvanitidis C (2013) Micro-computed tomography: Introducing new dimensions to taxonomy. ZooKeys 263: 1-45. doi: 10.3897/ zookeys.263.4261

Hertz A, Hauenschild F, Lotzkat S, Köhler G (2012) A new golden frog species of the genus Diasporus (Amphibia, Eleutherodactylidae) from the Cordillera Central, western Panama. ZooKeys 196: 23-46. doi: 10.3897/zookeys.196.2774

La Salle J, Wheeler Q, Jackway P, Winterton S, Hobern D, Lovell D (2009) Accelerating taxonomic discovery through automated character extraction. Zootaxa 2217: 43-55.

Sharkey M, van Noort S, Whitfield J (2009a) Revision of Khoikhoiinae (Hymenoptera, Braconidae). In: Johnson N (Ed) Advances in the systematics of Hymenoptera. Festschrift in honour of Lubomír Masner. ZooKeys 20: 299-348. doi: 10.3897/zookeys.20.108

Sharkey M, Yu D, van Noort S, Seltmann K, Penev L (2009b) Revision of the Oriental genera of Agathidinae (Hymenoptera, Braconidae) with an emphasis on Thailand and interactive keys to genera published in three different formats. ZooKeys 21: 19-54. doi: 10.3897/ zookeys.21.271

Stoev P, Akkari N, Zapparoli M, Porco D, Enghoff H, Edgecombe GD, Georgiev T, Penev L (2010) The centipede genus Eupolybothrus Verhoeff, 1907 (Chilopoda: Lithobiomorpha: Lithobiidae) in North Africa, a cybertaxonomic revision, with a key to all species in the genus and the first use of DNA barcoding for the group. ZooKeys 50: 29-77. doi: 10.3897/ zookeys.50.504

van Noort S, Johnson NF (2009) New species of the plesiomorphic genus Nixonia Masner (Hymenoptera, Platygastroidea, Platygastridae, Scelioninae) from South Africa. In: Johnson N (Ed) Advances in the systematics of Hymenoptera. Festschrift in honour of Lubomír Masner. ZooKeys 20: 31-51. doi: 10.3897/zookeys.20.112 